\title{
Evaluation Inquiry in Donor Funded Programmes in Northern Ghana: Experiences of Programme Staff
}

\author{
Bernard Afiik Akanpabadai Akanbang \\ University for Development Studies, Wa Campus, UWR, Ghana \\ bakanbang@uds.edu.gh, akanbang@yahoo.com
}

\section{Ibrahim Yakubu}

University for Development Studies, Wa Campus, UWR, Ghana

and

\section{Gordon Dugle}

Department of Administration and Management Studies, Wa Campus, UWR, Ghana

DOI//http://dx.doi.org/10.4314/gjds.v13i1.2

\begin{abstract}
An evaluation inquiry has been noted to have a significant influence on whether the evaluation outcomes are used or not. However, only limited studies have examined evaluation inquiry and its implication on the use of evaluation in Ghana. This study therefore seeks to contribute to knowledge on evaluation inquiry and the implications it has on evaluation use in Northern Ghana. Using a multistage sampling process as part of a broader study on evaluation inquiry and use in Northern Ghana, the study examined key elements of evaluation inquiry in 27 programmes implemented between the period 2000 and 2010 in Northern Ghana. Two main levels of data collection were carried out. The first level collected data on the programmes while the second level collected data from programme staff of three programmes as the units of enquiry. It emerged that evaluation was mostly externally funded, premium was placed on project completion evaluation; and evaluation was more an external accountability driven activity. The potential of mid-term evaluation to contribute to evaluation use was undermined by the tag associated with it as basis for the termination of programmes. The study therefore recommends building the evaluation capacity of staff and professionalization of evaluation practice in the country as a way of enhancing evaluation inquiry.
\end{abstract}

Keywords: Evaluation, Programmes evaluation, Evaluation inquiry, Evaluation use, Northern Ghana 


\section{Introduction}

Evaluation has been accepted as one of the ways of bringing effectiveness to development interventions (Morra, Linda \& Rist, 2009; Clements et al., 2008; Holvoet \& Renard, 2007; Newcomer, Hatry \& Wholey, 2010). In response to the growing need for and importance of evaluation, evaluation units or divisions have been established in most organisations, especially those involved in international development. In the same way, evaluation is demanded as a requirement of programmes for accessing funds (Hatry et al., 2010; Morra et al., 2009; Crawford \& Bryce, 2003).

However, whether an evaluation will provide the needed feedback required to improve upon performance or learning opportunities for organizations, depends upon the nature and characteristics of the evaluation inquiry. Recent discussions and research on evaluation use point to the importance of evaluation inquiry in influencing the use of evaluations (Akanbang et al., 2013b; Patton, 2008; Smits \& Champagne, 2008; Greene, 1988; Turnbull, 1999). Besides, increasingly, there are strong views that the evaluation inquiry in itself and depending upon how it is facilitated can result in certain uses occurring even before the final evaluation report is submitted (Akanbang et al., 2013; Greene 1988; Forss et al., 2002; Patton, 2008; Podems, 2007; King, 2007; Harnar \& Preskill, 2007).

Unfortunately, in spite of Africa and the rest of the developing world being home to numerous programme evaluations, Elbers, Gunning, Jan and de Hoop (2009) note that there is under-utilisation of evaluation research in Africa. Consequently, evaluation is yet to play a meaningful role in the development of Africa. Ghana's central planning agency, the National Development Planning Commission (NDPC), for instance, noted that there is still low demand for evaluation data and use of evaluation at the local level, even though different forms of monitoring and evaluation systems go on at this level (NDPC, 2010). Besides, only limited systematic efforts have gone into examining what constitutes programme evaluation inquiry in Ghana and the implications of the nature and characteristics of evaluative inquiry to the use of evaluation (Akanbang, 2012). The case of Northern Ghana is even more urgent because, there is the need to know what is being done right and wrong in terms of evaluation so that evaluation can contribute significantly to alleviating poverty in the area, which has so far proved insurmountable.

Thus, the study addresses the knowledge gap on evaluation inquiry in programmes in a developing country context and how the nature of evaluation inquiry affects the use of evaluation. Taking development programmes funded by international development assistance organizations and implemented by Ghanaian and international NGOs and by agencies of the Ghanaian government, this paper explores evaluation inquiry in Northern Ghana, a zone in which the guidelines for decentralised Monitoring and Evaluation (M\&E) have been piloted. The paper is based upon a survey of evaluation processes in 27 programmes and the experiences of 52 programme staff of three programme evaluations. 


\section{Evaluation}

Akanbang (2012) and Alaimo (2008) explored the various ways in which evaluation has been defined. Key elements gleaned from a review of the various definitions included; the recognition that evaluation is a systematic process for collecting information about the programme; it involves assessment - judging the worth or value of the programme; and the ultimate purpose of programme evaluation is to gather and use information to improve upon the programme (Alaimo, 2008 cited in Akanbang, 2012). The Development Assistance Committee Working Party on Aid Evaluation of the Organisation for Economic Cooperation and Development (OECD) provides one of the most widely used definitions of evaluation. It describes evaluation as: "an assessment, as systematic and objective as possible, of an ongoing or completed project, programme or policy, its design, implementation and results. The aim is to determine the relevance and fulfilment of objectives, developmental efficiency, effectiveness, impact and sustainability. An evaluation should provide information that is credible and useful, enabling the incorporation of lessons learned into the decisionmaking process of both recipients and donors" (OECD, 1991, p. 5 cited in Akanbang, 2012). In this paper, evaluation is defined as any conscious and orderly process of finding out the level of performance of development programmes, the factors responsible for their performance and the processes involved in generating and feeding the lessons into the programme development process with the view to enhancing the overall performance of the programme as well as improving the design and management of future programmes. Key in this definition is the emphasis placed on the feedback systems which are viewed as being essential to the use of evaluation.

\section{Importance of Evaluation}

The demand for programme evaluation, the subject matter of this paper, and defined as the application of systematic methods to respond to questions on programme operations and results through either ongoing monitoring of a programme and/or one-shot studies of programme process or programme impacts (Newcomer et al., 2010; Rossi, Lipsey \& Freeman, 2004) has seen phenomenal growth and interest (African Development Bank, Operations Evaluation Department, 2006; Andersen, Birchall, Jessen \& Money, 2006; and Kusek \& Rist, 2004 as cited in Leeuw \& Furubo, 2008). Increasing need and demand for public accountability both downwards and upwards (Newcomer et al., 2010; African Development Bank, 2006; Ferraro \& Pattanayak, 2006), the prominence given to evidence-based policy and the requirement for policy makers to develop prudent policies based upon a firm comprehension of the existing context (Davies et al., 2000; MacKenzie, Rivara, Jurkovich, Nathens, Frey, Egleston, Scharfstein, 2006; Martin \& Sanderson, 1999), demand for resultsbased budgeting and management and iterative learning in line with the new international development paradigm's principles (Holvoet \& Renard, 2007 and Engel, Carlsson \& Zee, 2003), increased desire by programme designers and implementers to be prudent in their use of scarce funds in the light of thinly stretched budgets for programmes (Ferraro \& 
Pattanayak, 2006), have contributed significantly to this growth in demand for programme evaluation.

Generally, it has been noted (Martin \& Sanderson, 1999; Bamberger \& Eleanor, 1986; and Conyers \& Hills, 1984) that evaluation systems provide feedback on goal achievements; initial problems identification as well as proposition of solutions; measuring equity and efficiency; and providing guidelines for the planning of future programmes. A review of the poverty reduction strategy approach by the World Bank and International Monetary Fund in September, 2005 underscored the centrality of a strong evaluation system for enhancing development effectiveness, reinforcing mutual accountability and realizing the Millennium Development Goals ( African Development Bank, 2006). Similarly, Andersen et al. (2006) found that successful project management, regardless of cultural differences, depended on professional planning and cost control, rich communication and learning from experience in order to achieve superior project success. Kusek \& Rist (2004) cited in Leeuw \& Furubo (2008) articulated that building an evaluation system adds the fourth leg to the governance chair which traditionally consisted of budget systems, human resource systems, and auditing systems. Building a monitoring and evaluation system brings to the fore the outcomes and consequences of governmental actions.

\section{Evaluation use and the Politics of Evaluation}

The importance of evaluation is seen in the establishment of evaluation units and departments within organisations as well as the professionalization of evaluation across continents. Besides, evaluation within the context of international development is demanded as a requirement of programmes for accessing funds (Hatry et al., 2010; Morra et al., 2009; Crawford \& Bryce, 2003) and account for about fifteen percent of programme funds. In developing countries, international donor agencies have mostly been at the forefront in championing evaluation efforts in the developing world for many reasons - need for accountability for the use of funds and to demonstrate results for the use of funds as basis for the continuous availability of funds to support their work. As a result, most evaluations conducted in the developing world are geared towards the needs of these organisations. Thus, the timely and useful feedback needed by programme managers from evaluation in developing countries to enable the continuous improvement of quality, scale, access, equity, and impact is lacking in most evaluations (McDonald, 1999; Thoenig, 2000 as cited in Forss, Rebien \& Carlsson, 2002). The Swedish International Development Agency, for instance, in an assessment of its evaluation practices, was disappointed to find that most stakeholders never saw the findings and that the few who did, found nothing very new or useful in them. The agency arrived at a conclusion that evaluation does not mean anything to the majority of programme staff and managers in the developing world (Bamberger, 2009). Alaimo (2008), Podems (2007) and Kusek and Rist (2004) had found earlier that evaluation was mostly used as a reporting requirement of funding institutions and remained overly centred on compliance with government requirements and regulations and 
on tracking of implementation of policies, programmes and projects, rather than end-results of policy, programme and project efforts. Besides, it has been observed that most evaluation processes are used as tools to cover up abuses and mistakes and to advocate or advertise for more funding (Lempert, 2010; House, 2008; Michaelowa \& Borrmann, 2006).

\section{Evaluation Inquiry}

Evaluation inquiry according to Cousins and Whitmore (1998) encompasses the purpose and type of the evaluation, the level of stakeholder involvement, and the methods employed in the evaluation among others (Cousins \&Whitmore, 1998 cited in Cousins et al., 2004). A key component of evaluation inquiry is the purpose of evaluation. According to Chelimsky (1997) and Patton (2008), the purpose of an evaluation determines the use that it will be put into. Evaluation is not conducted for any one purpose (Patton, 2008; Powell, 2006; Chelimsky, 1997). According to Chelimsky (1997), evaluation purposes are classified into three, namely: evaluation for accountability, evaluation for programme improvement and evaluation for knowledge generation.

Evaluation methodology or design as a key component of evaluation inquiry is very essential to the use of evaluation. Evaluation methodology sets out the strategy to be used for determining what results are attributable to the programme and what is learned from the evaluation. According to Newcomer et al. (2010), the strength and credibility of findings, conclusions and recommendations are founded on the evaluation design. Evaluation methodology or design refers to the logical model for assessing the programme. It encompasses a comprehensive process for collecting data, a definition of a framework for analysing data and for identifying results attributable to the programme, and processes involved in mainstreaming lessons into the current programme or in the planning and implementation of future programmes. Three forms of evaluation designs are common in programme evaluation; experimental, quasi experimental and non experimental designs (Christie \& Fleisher, 2010). There is no gold standard methodology for doing evaluation (Chelimsky, 1997). Each methodology and design has its strengths and short comings. Thus, different evaluation purposes employ a mix of evaluation methodology and design in order to enhance the validity and use of the evaluation or to make for the limitations of each other. Self evaluation or internal evaluation without independent validity checks is noted to be quite vulnerable because it introduces advocacy into the evaluation. Self evaluation also possesses high potential of loss of control of the evaluation by the evaluator. There are also uncertainties about the quality of the information produced. Randomized control experiments have been criticised for being adversarial rather than helpful in trying to improve policies and programmes.

Stakeholder involvement as an element of evaluation inquiry has received substantial attention in the evaluation literature as being central to the use of evaluation (Greene, 1988; Smits \& Champagne, 2008; Suarez-Herrera, Springett \& Kagan, 2009). However, what constitutes stakeholder involvement and which stakeholders to be involved has been a 
subject of controversy. Some evaluators are of the view that stakeholder participation introduces bias into the evaluation. The rise in performance or results-based management coupled with the desire to show value for money has also jeopardised the substantial involvement of stakeholders in evaluation (Estrella \& Gaventa, 1998; Bryson et al., 2011). This paper aligns itself with the description of stakeholder involvement in evaluation by the Canadian International Development Agency. The Agency describes stakeholder involvement as making key stakeholders to become integrally involved in setting up the systems for measuring and reporting on results, reflecting on results achieved, proposing solutions and responding to challenges, and promoting the implementation of evaluation recommendations (Canadian International Development Agency, 2004).

Greene (2005) and Rossi et al. (2004) elaborate on what evaluation stakeholders are. Rossi et al. (2004) for instance identified policymakers and decision-makers, programme sponsors, evaluation sponsors, target participants, programme managers, programme staff, programme competitors, contextual stakeholders, evaluation and research community as having an interest in an evaluation and should therefore be involved in the evaluation process. It is important to focus on a narrow list of potential stakeholders that form the group of what Patton (2008) refers to as primary intended users in an evaluation. In this study, the key stakeholders analysed are the programme staff.

\section{Conceptual Framework}

Figure 1 shows how an evaluation inquiry interacts with the policy or organisational setting and or the evaluation process in order to achieve different kinds of use.

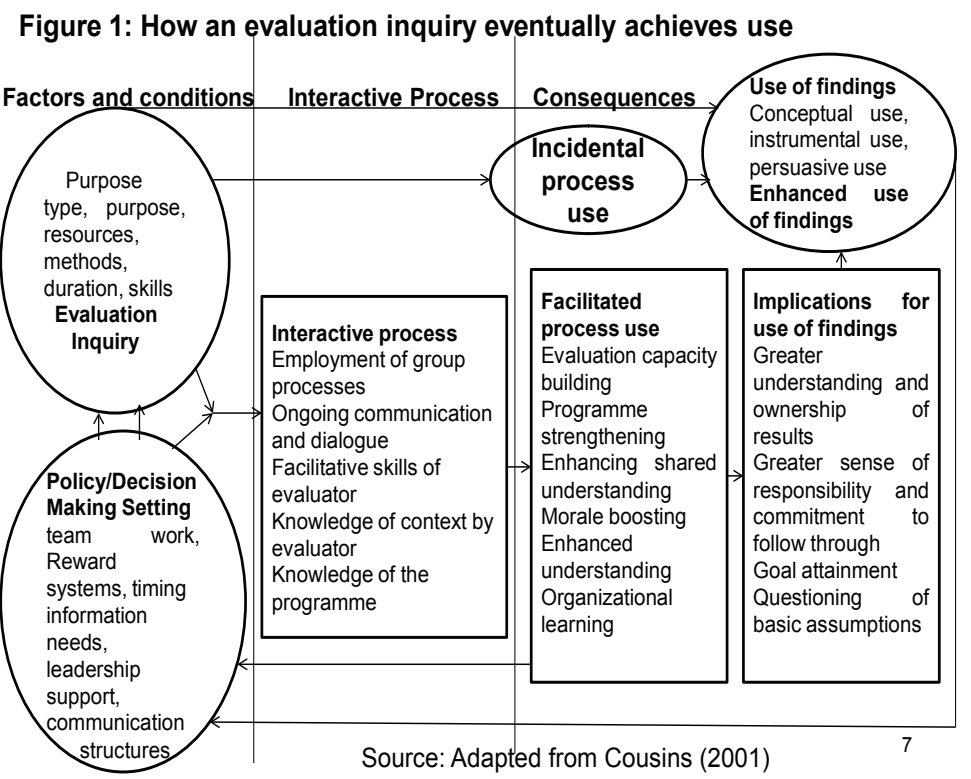


A significant principle underlying the framework is that, an evaluation once conceived, goes through a process and finally produces some outcomes. In line with this principle, the framework consists of three linked stages/components/elements identified as factors and initial conditions, process, and consequences, which are inherent in the frameworks of Smits and Champagne (2008) and Cousins et al. (2004). The first stage; factors and conditions consists of the policy or decision making setting and the evaluation inquiry (Amo \& Cousins, 2007; Cousins et al., 2004) or evaluation context as in Smits \& Champagne (2008).

The interaction that goes on between the evaluation inquiry and policy setting determines the form and depth of interaction that should take place among practitioners and between evaluators and practitioners in the evaluation process while the interaction that takes place in the evaluation determines the type and range of use that occur. Key issues involved in the kind of interaction that takes place in an evaluation in order to realize facilitated process use and enhanced use of findings have been acknowledged to include; the level of control among stakeholders of evaluation decision making, the level of diversity among participating stakeholders, the technical as well as interpersonal abilities of the evaluator, participants' level of knowledge of the programme, participants' level of commitment to the evaluation, evaluators' knowledge of the evaluation and programme context, and participants' knowledge and appreciation of evaluation (Smits \& Champagne, 2008).

Depending upon the nature of interaction, certain consequences are produced: use of findings (Amo \& Cousins 2007; Cousins et al., 2004; Greene, 1988; Smits \& Champagne, 2008); incidental process use (Amo \& Cousins, 2007; Cousins et al., 2004; Forss et al., 2002; Patton, 1997); facilitated process use and enhanced use of findings (Greene, 1988; Patton, 2008). Some of the consequences associated with process use include evaluation capacity building, that is, programme readiness to do and use evaluations (Amo \& Cousins, 2007; Cousins et al., 2004; King, 2007), morale boosting (Forss et al., 2002), networking (Forss et al., 2002), strengthening of projects/programmes (Patton, 2008, Forss et al., 2002), and shared understanding (Patton, 2008; Forss et al., 2002).

Process use increases acceptance and ownership of evaluation findings and concomitantly a greater sense of responsibility and obligation to follow through on findings, culminating into enhanced use of findings (Greene, 1988; Smits \& Champagne, 2008). Process use also has such organizational consequences as goal attainment; problem solving and decision making; shared representation and questioning basic assumptions (Amo \& Cousins, 2007; Cousins et al., 2004). Process use and enhanced use of findings provide feedback to the policy setting that may lead to the reform of programme processes and organisational arrangements and ultimately the way the programme or organization will approach evaluation in the future. 


\section{Methodology}

The study is exploratory. It explored programme evaluation inquiry as part of a broader study on evaluation processes and use in Northern Ghana. Exploratory studies are conducted when a new topical area of interest is being examined or when the topic area is relatively new and unstudied or when the objective is to test the feasibility of undertaking a more careful study (Rubin \& Babbie, 1997, Ahiadeke, 2008). The study design is anchored in development programmes, which were implemented within the period 2000 and 2010 in Northern Ghana and have evaluations conducted on them between 2008 and 2011. The choice of the period 2008 to 2011 was to ensure that programme staff were still at post to enable them to be easily contacted. It also was to ensure that their experiences of the evaluation inquiry remained fresh on their minds. Northern Ghana was chosen because it provided a fertile ground for studying and analysing programme evaluation. The area attracts development programmes from the international development community because of the endemic poverty, hunger, malnutrition and infant mortality in the area, which is also known to be the three most deprived regions of the country (Ghana Statistical Service, 2008). The study was designed to collect data at two main levels. The first level data collection took place in December, 2010 and January, 2011 and was meant to provide the basis for determining the programme evaluations that were to be selected for the second level of the data collection. A multistage sampling process was adopted in the conduct of the study. The first stage of the sampling process involved the use of simple random sampling to select one administrative region out of the three regions that constitute Northern Ghana. Following this, all programmes implemented in Upper West Region between 2000 and 2010 were studied. In all, 31 programmes were implemented between 2000 and 2010. Some 84 percent of these programmes went through various forms of evaluation, of which 45 percent were evaluated between 2008 and the first quarter of 2011. Following the period criterion of the study design, eight programmes constituting 26 percent of the implemented programmes were qualified for selection. However, further analysis taking into consideration other criteria as the experience of process use in the evaluation; and the availability of at least twentyfive potential respondents at the programme level to participate in the study, reduced the number of programmes to three.

The criteria used to select the programme evaluations for the second level data collection were:

- the programmes and projects must have been implemented between 2000 and 2010;

- the programme must have a lifespan of at least four years; and

- the programme must have gone through one form of evaluation or the other within the period 2008 and the first quarter of 2011.

The outcome and output of this first level sampling and data collection were characteristics of 27 programmes and the nature of their evaluation inquiry. The nature of the programme evaluation inquiry identified at this level through the use of a combination of open 
and closed ended questionnaire and administered to programme managers is one of the sources of information for the paper. The bulk of the programmes came from Local Non-Governmental Organisations (LNGOs) (48\%) and those implemented by Ministries, Departments and Agencies (MDAs) (37\%).

Table 1 shows the programme evaluations in which the first survey was conducted and the agencies within which the programmes were implemented and evaluated.

Table 1: Profile of programme evaluations analysed

\begin{tabular}{|l|l|l|}
\hline Type of organisation & No. of programmes evaluated & Percent \\
\hline MDAs & 10 & 37 \\
\hline INGOs & 4 & 15 \\
\hline LNGOs & 13 & 48 \\
\hline Total & 27 & 100 \\
\hline
\end{tabular}

Source: Survey among programmes (2011)

Table 2 provides the organisational backgrounds of the respondents in the second survey. All staff who worked on the programmes were targeted to be consulted.

Table 2: Organisational background of respondents

\begin{tabular}{|l|l|l|}
\hline Type of organisation & No. of Respondents & Percent \\
\hline Regional Coordinating Councils & 8 & 15 \\
\hline MMDAs & 29 & 56 \\
\hline Departments and Agencies & 15 & 29 \\
\hline Total & 52 & 100.0 \\
\hline
\end{tabular}

Source: Survey among programme staff (2011)

The average age of respondents was 43 while on the average respondents participated in three programme evaluations and have been working on the programme for five years. Thirty-nine percent and 29\% of respondents respectively had Bachelors and Master Degrees, while only $13 \%$ and $19 \%$ had Diplomas and Certificates only respectively. Substantial numbers (56\%) had backgrounds in Development Studies. 


\section{Results and Discussions}

This section presents the results and discussion of data on evaluation inquiry in programmes in Northern Ghana.

\section{Evaluation Purpose}

As depicted in Table 3, 87\% of all programmes in the study had functioning evaluation as a component. Careful observation of the data showed that, only programmes with shorter durations, less than three years; and which were in response to emergencies did not have evaluation conducted on them.

Table 3: Status of evaluation in programmes

\begin{tabular}{|l|l|l|l|}
\hline \multirow{2}{*}{ Type of organisation } & \multicolumn{2}{|l|}{ No. of Programmes that have Evaluation } & \multirow{2}{*}{ Total } \\
\cline { 2 - 4 } & Number & Percent & \\
\hline Local NGO & 13 & 87 & 15 \\
\hline INGO & 4 & 80 & 5 \\
\hline MDAs & 10 & 91 & 11 \\
\hline Total & 27 & 87 & 31 \\
\hline
\end{tabular}

Source: Survey among programmes (2011)

The existence of evaluation in almost all the programmes is not surprising as aid agencies have over the years required evaluation as a major component of programmes for securing funding for development interventions. What is important, however, is not the existence of evaluation, but what the evaluation brings to the programme in terms of aiding in the achievement of programme goals and objectives.

It was discovered that $82 \%$ of programme staff perceive programme improvement as the main purpose of evaluation. They expected to learn lessons that will enable them to improve upon the performance of their programmes. Table 4 shows what programme staff perceive as the purpose of evaluation. An equally significant proportion of staff perceived the purpose of evaluation as merely fulfilling donor demands for upward accountability (70\%) and passing judgement on the performance of programmes (68\%). Evaluation for accountability was perceived as very important to donors because it provided them with information to enable them know whether their tax payers' monies were used for the benefit of the poor and were yielding expected returns and consequently whether additional resources should continue to be sunk into the programme or not. 
Table 4: Perception of programme staff on the purpose of evaluations

\begin{tabular}{|l|l|l|}
\hline Perception of programme staff & No. of Respondents & Percent \\
\hline Mandated by sponsor and has to fulfilled & 35 & 70.0 \\
\hline $\begin{array}{l}\text { Staff will learn lessons to improve upon } \\
\text { the programme }\end{array}$ & 41 & 82 \\
\hline $\begin{array}{l}\text { Meant to pass judgment on the performance } \\
\text { of the programme }\end{array}$ & 34 & 68 \\
\hline $\begin{array}{l}\text { To produce knowledge } \\
\text { To document the success story of the programme }\end{array}$ & 16 & 32 \\
\hline
\end{tabular}

Source: Survey among programme staff (2011)

Evaluation as a means for passing judgement on programmes was perceived by staff as a mechanism whereby the programme budget was arbitrarily curtailed. It was observed that evaluation for accountability or for judgement tended to undermine the cardinal purpose of evaluation as a programme improvement measure. It created a defensive posture in programme staff and made them passive to the evaluation process instead of being active participants in a process that will enable them to improve upon the performance of their programmes. It came out that in $85 \%$ of programmes, donors determined the purpose of the evaluation conducted on them.

\section{Evaluation Types}

Evaluation types prominent in programmes as shown in Table 5 include mid-term evaluation, programme completion evaluation, impact assessment, quarterly and annual reviews. These types of evaluation were conducted at the various stages in the life of the programme.

Table 5: Types of evaluation in programmes

\begin{tabular}{|l|l|l|}
\hline \multirow{2}{*}{ Type of evaluation } & Frequency of occurrence \\
\cline { 2 - 3 } & Frequency & Percent \\
\hline Impact assessment & 8 & 14 \\
\hline Mid-term evaluation & 11 & 19 \\
\hline Project completion & 18 & 31 \\
\hline Quarterly reviews & 6 & 10 \\
\hline Annual reviews & 7 & 12 \\
\hline Total & 50 & 100 \\
\hline
\end{tabular}

Source: Survey among programme staff (2011) 
Monitoring was observed to be institutionalised and given prominence in all the programmes. Monitoring activities included checking on service providers to ensure that they were delivering quality services and in accordance with contracts; checking on the quantum and timely delivery of the services and their spatial flow, as well as checking on staff by superiors or higher level organisations checking on lower level organisations to ensure compliance among others; and staff checking on functionality status of facilities. However, in many of the monitoring activities, no specialised tools or checklists were used. As a result there were often not enough bases for assessing whether progress was being made and whether feedback was being used.

Programme completion evaluation emerged as the dominant type of evaluation carried out in programmes. Project completion evaluation was carried out about six months before the end of the programme with the aim of determining the attainability of programme outcomes, efficiency and sustainability. It reports on the accomplishments of programmes in terms of outputs and early indicators of outcomes. Consequently, they were perceived as serving more the accountability needs of donors than programme improvement needs. Such an orientation affected the genuine interest and enthusiasm of staff in the evaluation process.

Mid-term reviews, in spite of the enormous potential they had in providing feedback into the programme during its life, were a less prominent type of evaluation in programmes. Similarly, quarterly and annual reviews even though institutionalised were not recognised by staff as major evaluation activities. This was mostly because of the perception of evaluation as an independent assessment involving an external person. These evaluation activities, however, were observed to be in a better position to uncover errors early which were immediately nipped in the bud before they escalated. Similarly, best practices were identified early and vigorously promoted in the programme. The different stakeholders from different organisations that met for the quarterly and annual reviews provided a platform for exchange of information and for learning to take place.

On-going evaluations which are usually special studies undertaken to deal with specific issues during the course of project implementation, and is a major input into mid-term evaluation and subsequently project completion evaluation, were also not prominent in programmes.

Another categorization of evaluation is whether they are conducted internally by organisations implementing the programme or externally by consultants. As shown in Figure 2, almost $96 \%$ of the evaluations were conducted externally by private consultants. The use of external evaluators was perceived to add credibility to the evaluation and to allow for a different opinion to be brought to bear on the programme. The use of an external person was also perceived as providing an opportunity for programme management or staff to make a case for changes in some programme aspects which adversely affected its performance but which management or donors have been reluctant to change. 
Figure 2: Internal verses external evaluations

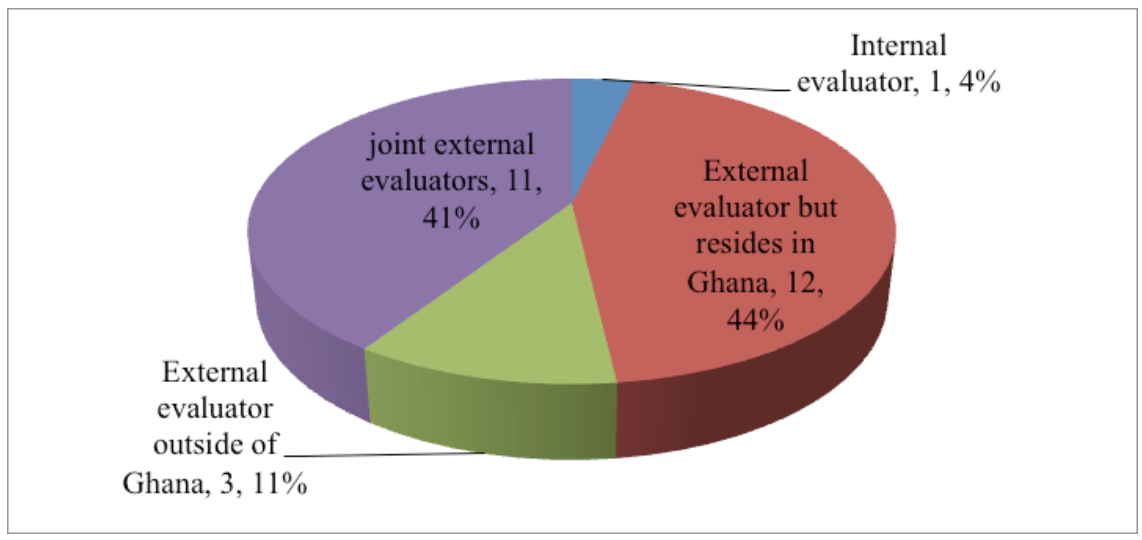

Source: Survey among programmes (2011)

An external person also provided a platform for staff to talk about the programme dispassionately, mindful that they would not be victimised. However, a major challenge noted with the use of external evaluators by respondents related to the limited time available to them to do their work. A respondent commented on the use of external evaluators, thus: 'they often do not have ample time to interact with us. Consequently, much probing and triangulation was not usually undertaken; nonverbal communications were not properly understood resulting in misrepresentations and conclusions and recommendations which stall programme progress and mar the reputation of organisations' (Interview with Progamme Manager, April, 2011). Most internally conducted evaluations were the quarterly and annual reviews. In spite of the benefits associated with them as noted earlier, they suffered credibility problems. Besides, issues of perceived sensitivity, management may also be stifled under internal evaluations for fear of victimisation. The way forward for deriving value from both externally and internally conducted evaluations is to ensure a marriage between the two types of evaluations. It was observed that in two of the programme evaluations in which detailed studies were conducted, the evaluation teams consisted of both external and internal persons.

As was shown in Figure 2, there was significant local content in the conduct of evaluations. Cumulatively, local content was inherent in $85 \%$ of evaluations conducted. It was observed that there was partnership between Ghanaian and foreign evaluators in $41 \%$ of evaluations. Joint evaluations allow for local content into evaluations and for the maximisation of the benefits associated with foreign and local evaluators. Sixty percent of MDAs' programmes were evaluated through joint evaluations, compared to $39 \%$ for local NGOs and none for International NGOs. The high percentage of MDAs' programmes using joint evaluation was directly related to the OECD policy that sought to develop in-country evaluation capacity through partnerships. 


\section{Funding of Evaluations}

Evaluations were mainly externally financed as shown in Table 6.

Table 6: Sources of funds for evaluations

\begin{tabular}{|c|c|c|c|c|c|}
\hline \multirow[t]{3}{*}{ Type of organisation } & \multicolumn{4}{|c|}{ Sources of funds for evaluations } & \multirow{3}{*}{ Total } \\
\hline & \multicolumn{2}{|c|}{ From programme funds } & \multicolumn{2}{|c|}{ Separate funds (donor) } & \\
\hline & Frequency & Percent & Frequency & Percent & \\
\hline Local NGO & 7 & 54 & 6 & 48 & 13 \\
\hline INGO & 4 & 100 & $\mathrm{O}$ & & 4 \\
\hline MDAs & 9 & 90 & 1 & 10 & 10 \\
\hline Total & 20 & 74 & 7 & 26 & 27 \\
\hline
\end{tabular}

Source: Survey among programmes (2011)

Seventy-four percent of programme evaluation funds came as part of the budget for the programme. This was a significant development in that it gave some degree of control to programme management on funding of evaluation. This makes the evaluator accountable to the programme more than to the donor and therefore gives management some influence over the evaluation process. Such funding arrangements have the potential to ensure that evaluation inquiry addressed the specific needs of programme implementers for the improvement of the programme. In spite of this development, it was realized from the three selected programmes that, in only one of them, was local management involved in contract management of the process. Local programme managers should use the opportunity of having control over the budget for evaluations to assert themselves and profile local information needs in the evaluations they undertake.

On the proportion of programme funds that go into evaluations, it was revealed that about $74 \%$ of evaluations reported a proportion below $15 \%$ which is the conventional amount of funding for programme evaluations. Funding for evaluations has been noted to be critical in determining key parameters of the evaluation including evaluation design and methods, among others (Bell, 2010). It also has implications for the quality and use of the evaluation (Patton, 2008). Table 7 shows the details of the proportion of funds in relation to total programme funds that go into evaluations. 
Table 7: Proportion of funds in relation to the programme that go into evaluations

\begin{tabular}{|c|c|c|c|c|c|c|c|c|c|}
\hline \multirow[t]{3}{*}{$\begin{array}{l}\text { Type of } \\
\text { organisation }\end{array}$} & \multicolumn{8}{|c|}{$\begin{array}{l}\text { Proportion of funds in relation to the programme that go into } \\
\text { evaluations }\end{array}$} & \multirow{3}{*}{ Total } \\
\hline & \multicolumn{2}{|c|}{ Less than $10 \%$} & \multicolumn{2}{|c|}{$10-15 \%$} & \multicolumn{2}{|c|}{$16-20 \%$} & \multicolumn{2}{|c|}{ Don't know } & \\
\hline & Freq & $\%$ & Freq & $\%$ & Freq & $\%$ & Freq & $\%$ & \\
\hline Local NGO & 4 & 31 & 3 & 23 & 4 & 31 & 2 & 15 & 13 \\
\hline INGO & 2 & 50 & 2 & 50 & o & & $\mathrm{o}$ & & 4 \\
\hline MDAs & 9 & 90 & $\mathrm{o}$ & $\mathrm{o}$ & 0 & & 1 & 10 & 10 \\
\hline Total & 15 & 56 & 5 & 18 & 4 & 15 & & 11 & 17 \\
\hline
\end{tabular}

Source: Survey among programmes (2011)

\section{Main Evaluation Participants in Programmes}

Evaluation participants included programme managers, staff, beneficiaries and funders. As shown in Figure 3,52\% of programmes had programme beneficiaries as the main participants in programme evaluations. This affirms the accountability and judgmental orientation of the evaluations. At the beneficiary level, evaluation questions seek to address how the programme has affected or is affecting the lives or activities of the beneficiaries. It is worth indicating that beneficiary involvement depending upon how it is carried out has the potential to build accountability systems in communities as well as bring a more pragmatic orientation to programmes and evaluations, and enhance cooperation at the operational level of programmes (CIDA, 2004).

Figure 3: Main evaluation participants in programmes

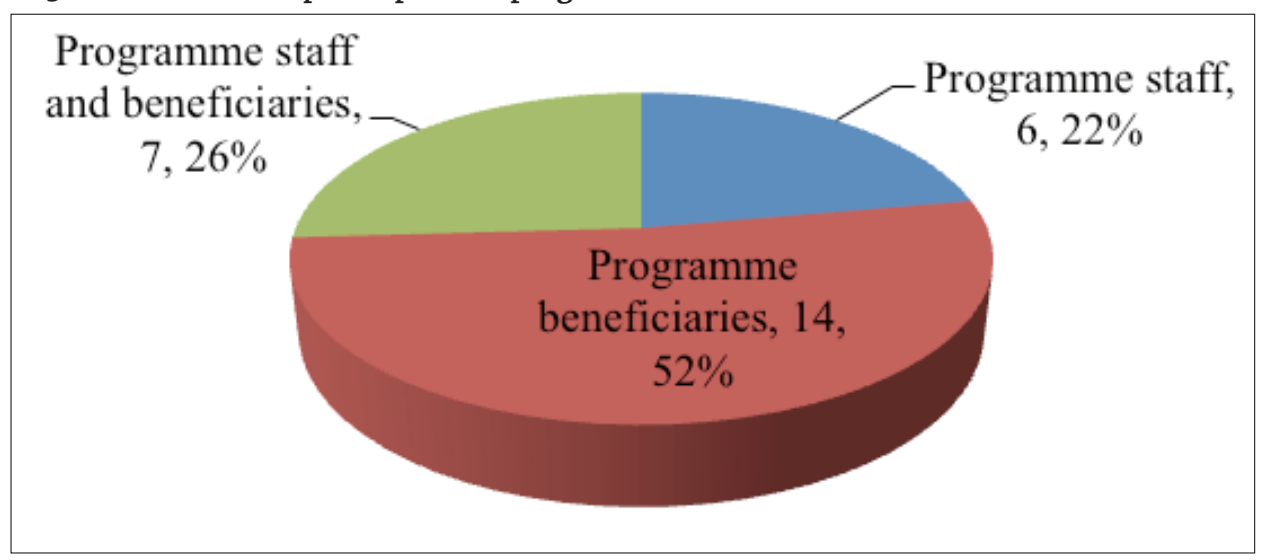

Source: Survey among programmes (2011)

Programme staff described by Paton (2008) as intended users of evaluations were not considered main evaluation participants in programmes. Programme staff should be at 
the heart of evaluation because they are the people who will use the evaluation results to improve upon their programmes. In spite of the numerous benefits of involving programme staff in the evaluation process, programme staff's involvement in the evaluations were basically in the area of facilitating interactions with beneficiaries and sometimes responding to some questions and participating in debriefing sessions. In only limited evaluations (4\%) were programme staff and managers involved in the design of evaluation questions and structure.

\section{Methods Used to Involve Programme Staff in Evaluation}

Focus Group Discussions (FGDs), personal interviews, participant observation and the formation of a taskforce were methods used to involve programme staff in the evaluations as shown in Table 8.

Table 8: Methods used to involve programme staff in evaluations

\begin{tabular}{|l|l|l|}
\hline Type of method & No of Respondents & Percent \\
\hline Personal Interviews & 32 & 64 \\
\hline FGDs & 39 & 78 \\
\hline Participant Observation & 10 & 20 \\
\hline $\begin{array}{l}\text { Member of taskforce involved } \\
\text { in design of evaluation }\end{array}$ & 2 & 4 \\
\hline
\end{tabular}

Source: Survey among programme staff (2011)

However, the use of taskforce as medium of involvement for enhancing the use of evaluations as recommended by Newcomer et al. (2010) and Hatry et al., (2010) was of limited use. Only $11 \%$ of evaluations indicated that they used it. The use of FGDs and participant observation were found to promote effective interaction among evaluation participants. A programme staff had this to say on the use of focus group for information gathering: 'the use of FGDs allows for the gathering of wide range of opinions and experiences, consensus building, shared understanding and the building of networks among evaluation participants'(Interview with programme staff, April, 2011)

\section{Evaluation Reporting}

Most programme staff (82\%) indicated that they got to know the outcomes of the evaluation through validation workshops. Only $48 \%$ of staff said they got to know the findings through a report. The debriefing sessions with programme managers and staff was found to be very useful. A comment from a programme staff elaborates the importance of the debriefing sessions: 'The debriefing sessions afforded us and the evaluator the opportunity to come to a common understanding of the findings, conclusions and recommendations of the evaluation which is necessary for their successful implementation.' The debriefing session was also observed to be 
an important medium for achieving wide dissemination of evaluation findings compared to the evaluation report. Besides, it was observed as courteous to let people whom information has been collected to comment on it before concretising it into a report.

Of the $48 \%$ of respondents who indicated the report as their source of information, only $40 \%$ read the report, thus affirming the view in the literature that, the evaluation report as a main source of disseminating evaluation information to participants is not very effective (Bamberger, 2009). One of the reasons for the limited access to the evaluation report is its treatment as a confidential document. Our observation during this study showed that the evaluation report was more often accessible to only a few privileged people. It was observed from respondents that, it was during the process of data gathering for this study that they looked for the report. One of the respondents indicated that the report was not accessible to all. He said he had access to the report by virtue of him being a steering committee member of the programme. To overcome the limited accessibility to the evaluation report, the report should be customised to meet the various needs and requirements of the different stakeholders. Classified information meant for specific people can be taken off the main report, thus making the report less harmful to the programme and organisation when it falls into wrong hands as a result of the wide dissemination of the report.

Of the 52 programme staff who participated in the three evaluations, about half (54\%) discussed the evaluation findings as a group. In the view of programme staff, if evaluation is to contribute to organisational learning and development, effective ways through which evaluation findings are shared and integrated in the programme or organisation have to be sought. Just merely giving a brief report at routine staff meetings may not be enough to digest and integrate evaluation findings in organisations. Setting apart a special day or holding a workshop or seminar on the evaluation for all staff, could be one effective way of sharing evaluation while allowing for the assimilation and integration of the findings in the programme or organisation.

\section{Conclusions and Recommendations}

This paper brings to the fore the need to create internal demand for evaluation in organisations and programmes. The dominance of end of programme evaluation as a major evaluation type, evaluation being a mandatory requirement of programmes, as well as programme staff perception and attitude towards evaluation as a fulfilment of donor requirements showed that evaluation was still externally influenced. If evaluation is to contribute to programme improvement and organisational development, efforts at promoting demand for evaluation internally such as mainstreaming process use in evaluation, building evaluation capacity of staff and professionalization of evaluation will be required to compliment the emerging initiatives as joint conduct of evaluation, mid-term evaluation and quarterly and annual reviews, which are all geared towards programme enhancement. 
The need for capacity building of programme staff in evaluation for maximum benefits to be derived from evaluations is also recognised by this paper. This would not only prevent the wrong perception programme staff have about evaluation as an added on activity but enable them to take advantage of emerging evaluation processes as quarterly and annual reviews, which provide immediate feedback into programme processes. The programme staff capacity needs to be built in programme theory so that the various activities they do in the programme will not be considered as merely fulfilling programme or donor demands. When programme staff capacity is built in evaluation, they will come to a fuller understanding that the manner in which programme activities are implemented have influence on the outcome of programme activities, so that they will take evaluation more seriously.

The effect that mid-term evaluation had on programme processes and outcomes was significant, even though, its full potential is undermined by the view held that, it provides the basis for deciding on the continuation or curtailment of the programme. To tap the enormous potential of mid-term evaluations, it should be delinked from the decision on the continuation or otherwise of the programme. Programme planners should design programmes with a clear period required to ensure that the programme is able to create the needed effect. Mid-term evaluation is then incorporated as a process for improving upon the programme rather than as a means of deciding on the fate of the programme. Other periodic assessments such as the quarterly and annual reviews should be adequately integrated and appropriately facilitated as a way of complementing the existing evaluation processes to ensure that the threefold purpose of evaluations - accountability, improvement and knowledge generation are achieved.

On the involvement of programme staff in evaluation, it was found that staff involvement in evaluation, especially at the initial stages of the evaluation was very useful in ensuring buy-in and ownership and consequently the use of the evaluation. Consequently, there is the need to consciously involve programme staff beyond linking evaluators to programme beneficiaries to actively engaging them in the evaluation design, implementation and analysis. Two to three days of quality time with staff to create the necessary rapport with them, and maintain a functioning communication with staff and programme management will ensure that staff participate actively in the process in order to yield benefits such as quality of the evaluation findings and consequently the use of the evaluation.

The evaluation report was still highly recognised as the most reliable source of information on actions that should be taken on the programme. In order to ensure the wide dissemination of the report, it is proposed that the report is customised for the different stakeholders so that particular information meant for limited audiences can be limited to only such people. The use of pre-departure debriefing with evaluation participants employing modern audio visuals should be made mandatory in evaluation assignments.

This study highlights the need for evaluation training and professionalization of evaluation practice in Ghana. Inadequate understanding of the 'real' purpose of evaluation resulting 
in scepticism on the part of programme staff, inadequate knowledge and skills required for evaluation and reliance on external evaluators among others bring to the fore the need for evaluation education and training and the professionalization of evaluation practice in the country. Currently, there are limited academic institutions that train people in evaluation. As a result, many of the people involved in evaluation have come from different backgrounds with their respective values and practices. The existence of a professional body would help to regulate the practice of evaluation among these diverse people; however, this is currently not functioning effectively, even though as part of the implementation of the Millennium Challenge Account in Ghana, efforts were made towards bringing evaluators in Ghana together, under the Monitoring and Evaluation Forum. Such efforts can ensure that evaluation standards and practices are mainstreamed in programmes in Ghana.

\section{References}

African Development Bank (2006). Monitoring and evaluation of poverty reduction strategies in regional member countries: Training needs assessment. Tunis: Operation Evaluation Department (OPED), pp. 1-17.

Ahiade, c. (2008). Research methodology: Theory and Practice in the Social Sciences Medina, Accra: Sundel services, pp. 1-15.

Akanbang, B. A. A. (2012). Programme Implementers experiences of process use in three programme evaluation contexts in Northern Ghana. A thesis submitted to university of ghana, accra in partial fulfilment of the requirements for the award of doctor of philosophy degree in development studies.

Akanbang, B. A. A., Darko, R. O. and Atengdem, P. B. (2013). Programme implementers' experiences of process use types in three evaluation contexts in Northern Ghana. Operant subjectivity, 36(4): pp. 270-292.

Alaimo, S. (2008). Programme evaluation capacity for non-profit human services organizations: An analysis of determining factors. A thesis submitted to the faculty of the university graduate school in partial fulfilment of the requirements for the degree doctor of philosophy in the department of philanthropic studies, Indiana University,https:// scholarworks.iupui.edu/.../DISSERTATION\%2OP... - United States.

Amo, C. and Cousins, B. J. (2007). Going through the process: an examination of the operationalisation of process use in empirical research on evaluation. In Cousins, B. J. (ed.), Process use in theory, research and practice: new directions for evaluation, pp. 5-26. San Francisco, California.

Andersen, E. S., Birchall, D., Jessen, S. A. and Money, A. H. (2006). Exploring project success. Baltic journal of management, 1(2), pp. 127-147. 
Bamberger, M. (2009). Enhancing the utilization of evaluations for evidence - based policymaking. In M. Segone (ed.). Bridging the gap: The role of monitoring and evaluation in evidence-based policy making, pp. 99-120. Geneva: Evaluation working papers.

Bamberger, M. and Eleanor, H. (1986). Monitoring and evaluating urban development programmes: A handbook for programme managers and researchers World bank technical paper no. 53. Washington, DC: World Bank.

Bell, J. B. (2010). Writing for impact. In J. S.Wholey, H. P. Hatry and K. E. Newcomer (eds.). Handbook of practical programme evaluation (Third Edition), pp. 594-619. San Francisco, CA, 94103-1741: John Wiley and Sons Inc. Jossey-Bass.

Bryson, J. M., Patton, M. Q. and Bowmanc, R. A. (2011). Working with evaluation stakeholders: a rationale, step-wise approach and toolkit. Evaluation and program planning, 34, pp. 1-12.

Canadian International Development Agency (October, 2004). CIDA evaluation guide. Toronto: Evaluation division, Performance and knowledge management branch, pp. $3-83$.

Chelimsky, E. (1997). Thoughts for a new evaluation society. Evaluation, 3(1), pp. 97-109.

Christie, C. A. and Fleischer, D. N. (2010). Insight into evaluation practice: a content analysis of designs and methods used in evaluation studies published in North American Evaluation-Focused Journals. American journal of evaluation, 31(3), pp. 326-346.

clements, P., Chianca, T. and Sasaki, R. (2008). Reducing world poverty by improving evaluation of development aid. American journal of evaluation, 29 (2), pp. 195-21.

Conyers, D. and Hill, P. (1984). An introduction to development planning in the Third World. Chichester: John Wiley \& Sons, pp.219-224.

Cousins, B. J., Goh, S. C., Clark, S. and Lee, L. E. (2004). Integrating evaluative inquiry into the organizational culture: A review and synthesis of the knowledge base. The Canadian Journal of Program Evaluation, 19 (2), pp. 99-14.

Cousins, J. B. (2001). Participatory evaluation up close (online). Available at www.sqep.ca/ archives/presentations/Cousinsb_colsqepo1.pdf. Accessed: 20 October 2010.

Cousins, J. B. and Whitmore E. (1998). Framing participatory evaluation. In E. Whitemore (ed.) Understanding and practicing participatory evaluation: New directions for evaluation, 80 (3), pp. 5-23. San Francisco: Jossey-Bass.

Crawford, P. and Bryce, P. (2003). Project monitoring and evaluation: A method for enhancing the efficiency and effectiveness of aid project implementation. International journal of project management 21(5), pp. 363-373. 
Davies, P. T., Holmes, E. and Wolf, F. (2000). An organisational framework for preparing and maintaining systematic reviews in education. Paper presented at the inaugural meeting of the campbell collaboration, Philadelphia, Pennsylvania, February 25-26, 2000.

Elbers, C., Gunning, J. W. and de Hoop, J. (2009). Assessing sector-wide programmes with statistical impact evaluation: A methodological proposal. World Development, 37(2), pp. $513-520$.

Engel, P.G.H., Carlsson, C. and van Zee, A. (2003) Making evaluation results count: internalising evidence by learning. Policy management brief No. 16. Maastricht, Netherlands: European centre for development policy management.

Estrella, M. and Gaventa, J. (1998). Who counts reality? Participatory monitoring and evaluation: a literature review. Brighton: Institute of development studies, at the University of Sussex, pp. 1-70.

Ferraro, P. J. and Pattanayak, S. K. (2006). Money for nothing? A call for empirical evaluation of biodiversity conservation investments PLoS Biol 4(4).

Forss, K., Rebien, C. C. and Carlsson, J. (2002). Process use of evaluations types that precede lessons learned and feedback. Evaluation, 8(1), pp. 29-45.

Ghana Statistical Service (2008). Ghana living standards survey of the fifth round (online). Available at www.statsghana.gov.gh/docfiles/glss5 report.pdf. Accessed: 20 October, 2010.

Greene, J. G. (1988). Stakeholder participation and utilization in programme evaluation. Evaluation Review, 12(2), pp. 91-116.

Harnar, M. A. and Preskill, H. (2007). Evaluators' descriptions of process use: an exploratory study. In B. J. Cousins (ed.). Process use in theory, research and practice: New Directions for Evaluation, 116, pp. 27-44. San Francisco, California.

Hatry, H. P., Wholey, J. S. and Newcomer, K. E. (2010). Evaluation challenges, issues and trends. In J. S. Wholey, H. P. Hatry and K. E. Newcomer (Eds.). Handbook of practical programme evaluation (Third Edition), pp. 668-680. San Francisco: John Wiley and Sons Inc. Jossey-Bass.

Holvoet, N. and Renard, R. (2007). Monitoring and evaluation under the PRSP: Solid rock or quicks sand? Evaluation and programme planning, 30(1), pp. 66-81.

House, E. R. (2008). Blowback consequences of evaluation for evaluation.American Journal of Evaluation, 29(4), pp. 416-426. 
King, J. A. (2007). Developing evaluation capacity through process use. In B. J. Cousins (Ed.). Process use in theory, research and practice: new directions for evaluations 116, pp. 45-60. San Francisco, California.

Leeuw, F. L. and Furubo, J. E. (2008). Evaluation systems: what are they and why study them? Evaluations, 14 (2), pp. 157-169.

Lempert, D. H. (2010). Why government and non-governmental policies and projects fail despite evaluations: an indicator to measure whether evaluation systems incorporate the rules of good governance. Journal of Multi-Disciplinary Evaluation, 6(13), pp. 58-109.

\section{MacKenzie, E. J., Rivara, F. P., Jurkovich, G. J. Nathens, A. B., Frey, K. P., Egleston,}

B. L., Salkever, D. S. and Scharfstein, D. O. (2006). National evaluation of the effect of trauma- center care on mortality. N Engl J Med, pp. 354-366.

Martin, S. and Sanderson, I. (1999). Evaluating public policy experiments: measuring outcomes, monitoring progress or managing pilots? Evaluation, 5(3), pp. 245-58.

McDonald, D. (1999) Developing guidelines to enhance the evaluation of overseas development projects. Evaluation and program planning, 22, pp. 163-174.

Michaelowa, K. And Borrmann' A. (2006). Evaluation bias and incentive structures in biand multilateral aid agencies. Review of development economics, 10(2), pp. 313-329.

Morra I., Linda G. Rist, R. C. (2009). The road to results: designing and conducting effective development evaluations. Washington: World Bank.

National Development Planning Commission (2010). Medium-term national development policy framework: Ghana shared growth and development agenda (GSGDA), 2010-2013 volume 1: policy framework final draft. Accra: NDPC.

Newcomer, K. E. and Hatry H. P. (2010). Pitfalls in evaluations. In In J. S. Wholey, H. P. Hatry and K. E. Newcomer (Eds.). Handbook of practical programme evaluation (Third Edition), pp 557-580. San Francisco, CA, 94103-1741: John Wiley and Sons Inc. Jossey-Bass.

Newcomer, K. E, Hatry, H. P. and Wholey, J. S. (2010). Planning and designing useful evaluations. In J. S. Wholey, H. P. Hatry and K. E. Newcomer (Eds.). Handbook of practical programme evaluation (Third Edition), pp. 5-29. San Francisco, CA: John Wiley and Sons Inc. Jossey-Bass.

Patton, M. Q. (2008). Utilisation focused evaluation ( $4^{\text {th }}$ Ed.). Thousand Oaks, California Sage publications, pp. 1-97.

Podems, D. R. (2007). Process use: a case narrative from Southern Africa. In B. J. Cousins (ed.). Process use in theory, research and practice: new directions for evaluation. San Francisco, Californai, pp. 87-97. 
Powell, R. R. (2006). Evaluation research: an overview. Library Trends, 55(1), pp. 102-120.

Rossi, P. H., Lipsey, M. W. and Freeman, H. E. (2004). Evaluation: a systematic approach (7 $7^{\text {th }}$ Edition). Thousand oaks, California: Sage publications, pp. 1-97.

Rubin, A. and Babbie, E. (1997). Research methods for social work. Pacific grove, CA: Brooks/ Code Publishing Company.

Smits, P. A. and Champagne, F. (2008). An assessment of the theoretical underpinnings of practical participatory evaluation. American Journal of Evaluation, 29, pp. 427-442

Suarez-Herrera, J. C., Springett, J. and Kagan,C. (2009). Critical connections between participatory evaluation, organizational learning and intentional change in pluralistic organizations. Evaluations 3(15), pp. 321-342.

Turnbull, B. (1999). The mediating effect of participation efficacy on evaluation use Evaluation and Program Planning, 22(2), pp. 131-140. 